\title{
Membrana: uma interferência experimental têxtil
} Membrane: an experimental textile interference

Mônica de Queiroz Fernandes Araúijo Neder Doutora, Universidade Federal de Juiz de Fora, MG monicaneder@gmail.com 


\section{Membrana: uma interferência experimental têxtil}

Membrane: an experimental textile interference

Mônica de Queiroz Fernandes Araújo Neder

\section{Resumo}

Este artigo é o registro de uma prática experimental realizada sobre substrato têxtil, que objetivou a manipulação de superfícies em projetos mutáveis, flexíveis e transitórios. O conceito foi construído a partir de reflexões sobre as formas tradicionais de uso dos objetos, em situações de privacidade, e a interação entre interior e exterior. O método construtivo utilizado foi o Miura-ori e o processo experimentado foi o da plissagem artesanal. Como resultado, apresentamos o objeto "membrana" que, de maneira sensorial e poética, foi manuseado em diferentes situações e formatos, comprovando a possível transitoriedade das superfícies têxteis.

Palavras-chave: flexível, mutável, sensorial

\section{Abstract}

This article is the record of an experimental practice performed on textile substrate, aiming the manipulation of surfaces in mutable, flexible and transient projects. The concept was constructed from reflections on the traditional ways of using objects, in privacy situations, and the interaction between interior and exterior. The constructional method used was the Miura-ori and the process was handcrafted. As a result, we present the object "membrane" that, in a sensorial and poetic way, was handled in different situations and formats, proving the possible transitoriness of the textile surfaces.

Keywords: flexible, changeable, sensory 


\section{Introdução}

O ambiente mutável e fluido é repleto de codificações e intrincadas representações dos relacionamentos sociais. Por conseguinte, nada mais natural do que refletir sobre como criar e desenvolver objetos carregados de significados. Isto torna pertinente o questionamento sobre os métodos lineares baseados em soluções de problemas e que, com dificuldade, atendem aos desejos dos consumidores em expressar as suas emoções, sentimentos e atitudes e atender situações fluidas e variáveis. A vontade de investigar um processo criativo diferenciado motivou a pesquisa do grupo Cor e Forma, do Instituto de Artes e Design, da Universidade Federal de Juiz de Fora, MG, sobre teoria e prática de novas formas de criar, propostas por Yázigi (2005) e Gassel (2016).

O grupo Cor e Forma faz parte do Diretório de Grupos de Pesquisa na Plataforma Lattes do CNPq e é coordenado pela Profa. Dra. Mônica de Queiroz Fernandes Araújo Neder. Ele pertence ao Laboratório Cor e Forma da referida Instituição. Seus estudos e experimentos práticos têm como uma das áreas de interesse a relação entre objetos mutáveis e o sujeito que percorre diferentes lugares e momentos. Em reuniões realizadas no laboratório, ao longo de $2016 \mathrm{com}$ alunos voluntários do Bacharelado Interdisciplinar em Artes e Design e do Bacharelado em Moda, exploramos as possibilidades de projetos versáteis, leves, mutáveis, flexíveis e transitórios, que apresentam novas formas e interações. Questionamos as maneiras tradicionais de usar as coisas após os estudos do texto de Erner (2005). Pensamos no emprego das vestimentas e objetos em diferentes situações verificadas entre o dentro/fora, o público/privado, ao longo das mudanças climáticas e do passar do dia. Refletimos sobre propostas que atendiam ao nomadismo contemporâneo e a conexão ao lugar, como visto em Maffesoli (2014).

O grupo definiu, após as reuniões de estudos, que iniciaria uma série de encontros criativos para tornar tangível o que a reflexão tornou possível: a construção de objetos vestíveis que tivessem seu uso determinado pelo sujeito. Esta coautoria - usuário e criador - gerou uma dificuldade em relação aos métodos lineares de projeto que tem como objetivo a solução de um problema. Como não tínhamos um problema e nem buscávamos uma solução, a aplicação da pesquisa realizada nos colocou diante de possibilidades inovadoras baseadas em situações transitórias com o uso de objetos mutáveis. Diante deste desafio, Gassel (2016) 
apresenta um percurso criativo rico de alternativas, pois solta o "freio" de propostas assertivas e libera a criação para o impensado, inusitado e, porque não, inovador.

O percurso criativo adotado pelo grupo, mais especificamente pelos alunos Grégori Castelhano e Bruna Gonçalves, incluiu algumas sessões de hansdtorm (Gassel, 2016), nas dependências do Laboratório, além de prospecção de materiais, métodos construtivos e sessões de uso documentadas em imagens e fashion film concebido pelos alunos supracitados.

\section{Percurso criativo da Membrana}

A leitura feita pelo grupo dos autores mencionados levantou muitas dúvidas sobre como seriam iniciados os encontros de criação e construção das propostas. O desafio de realizar algo tão diferente do conhecido gerou alguma insegurança nos alunos, que aceitaram o desafio de experimentar novos caminhos.

Como método no percurso criativo, utilizamos o handstorm, explicado por Gassel (2016) como parte do processo em um design colaborativo, onde uma equipe multidisciplinar desenvolve um determinado projeto. Nele, são contempladas diferentes alternativas construtivas e características de materiais. O que nos interessou, particularmente, no instrumento e que nos levou a adaptá-lo a uma prática experimental em moda, foi a sessão de estímulos visuais interpretada de diferentes formas e realizada ao longo de vários encontros. Neles, partindo de dúvidas do projeto, foram construídos modelos de forma improvisada e com materiais inusitados, que contribuíram para a criação de novos valores para os alunos. Esta prática experimental iniciou com o objetivo específico de construir objetos metafóricos para atender às demandas das situações variáveis de dentro e fora e posterior análise na busca de respostas. No passo seguinte, selecionamos uma proposta e trabalhamos para um destino real de apropriação pelo usuário. Assim nasceu a ideia da Membrana, objeto têxtil quase animado e flexível, cujo escopo foi o de se integrar ao usuário e proporcionar uma interação poética de coautoria ao ser vestida.

Após os encontros onde foram realizadas as sessões de estímulos, os alunos foram orientados a pesquisarem métodos construtivos e materiais, a fim de realizarem protótipos que direcionariam a construção do objeto final. 


\section{Processo Construtivo da Membrana}

A característica principal do objeto proposto, flexibilidade, fez o grupo pesquisar diferentes materiais e processos construtivos, com o objetivo de fazer uma seleção mais adequada ao propósito: construir algo que fosse vestível e permitisse a sua transformação em diferentes usos. As discussões caminharam em várias direções. Desde tecidos tecnológicos até impressões 3D. Diante de dificuldades executivas, decidimos utilizar algo que não limitasse o projeto às disponibilidades de tecnológicas e de matérias primas experimentais. Isto posto, nos voltamos para a pesquisa de processos tradicionais com substratos de fácil aquisição, que nos encaminharam para a milenar técnica do origami. Esta antiga tradição japonesa, que consiste na dobradura de papel, nos chamou a atenção porque transmite à superfície plana, formas tridimensionais que poderiam envolver o corpo.

Por ser uma dobradura que adquire uma forma estática, o origami colocou o grupo diante de um problema, ganhamos estrutura, mas perdemos flexibilidade. Perante este fato, expandimos a pesquisa sobre a técnica e nos deparamos com o Miura-ori ou dobradura Miura (Hellmuth, 2009 e Miura, 2009). Ela foi criada pelo astrofísico japonês Koryo Miura nos anos 1980, no Instituto Espacial e Aeronáutico da Universidade de Tóquio no Japão, com o objetivo de robotizar a contração de painéis solares quando lançados para o espaço. Este tipo de dobra, com vales e topos geometricamente bem delimitados, torna a superfície menos rígida, diminuindo a sua área, além de permitir que ela se expanda de um pedaço bem pequeno para um maior, e em diferentes direções, mantendo a forma tridimensional, mas maleável. Este avanço na técnica milenar permitiu a manipulação de diferentes materiais e inspirou o grupo para utilizá-la como base das experimentações práticas que levassem ao conceito estruturado nas reflexões iniciais do projeto.

Como parte integrante e não menos importante do processo construtivo, pesquisamos formas de fixação do diagrama do Miura-ori no substrato têxtil, por se tratar, a membrana, de um objeto vestível. Esta etapa deveria ser definitiva, o que logo nos fez descartar a engomagem do tecido para posterior dobradura, pois ela se desfaz com a lavagem. O pensamento seguinte foi a termo fixação de polímeros têxteis, que seguisse o princípio inicial de acessibilidade de materiais definido pelo grupo. A pesquisa nos levou para a plissagem artesanal como parte da construção do objeto. Este processo consiste na fixação definitiva de dobras sobre um tecido, a 
partir da aplicação de calor, vapor e pressão, com ferro de passar (prensados manualmente) ou equipamentos específicos (plissados à maquina).

A complexidade do Miura-ori nos encaminhou para uma plissagem do tipo sanduiche, desenvolvida pelos franceses no século XIX. Neste processo, utiliza-se um papelão em cada lado do tecido (moldes), já com o diagrama da dobradura executado, que ao se encaixarem, forçam o tecido a dobrar-se. Quando assim agrupados, são fixados por meio de pregadores de madeira e sofrem o processo de calor em estufa e posterior retirada dos moldes, fazendo com que o material adquira propriedades como expansão, retração e textura em toda superfície, sem perder tais características após a sua lavagem.

Escolhido o método construtivo, iniciamos a pesquisa dos materiais têxteis disponíveis e de fácil aquisição. Um fato que contribuiu para a seleção do substrato foi o problema de fixação da dobradura. Precisávamos de uma composição de fibras que permitisse a estabilização do diagrama projetado e milimetricamente calculado (figura 1). O material escolhido foi um tecido com armação do tipo tela, em $100 \%$ poliéster e com baixa densidade. Ele se destaca pelo caimento e acabamento e possui características de leveza e transparência. Para a confecção dos moldes foi utilizado papel do tipo pardo com gramatura de $45 \mathrm{~g}$, presos ao tecido por pregadores de madeira (figura 2). A termo fixação foi conseguida em forno caseiro, aquecido a $200^{\circ}$ durante 10 minutos.

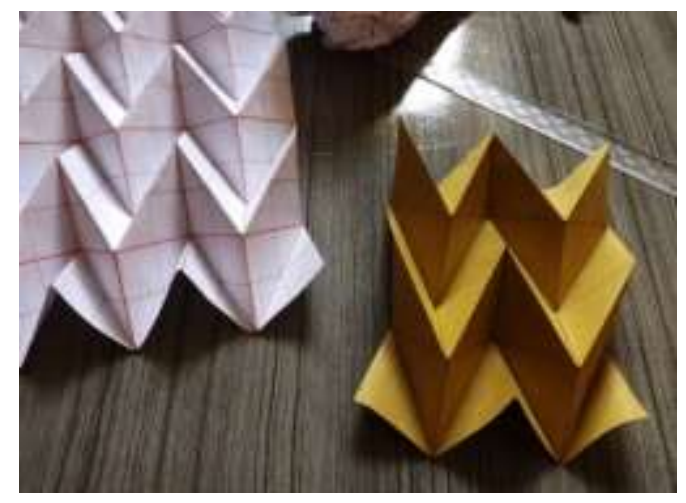

Figura 1: Miura-ori: dobra do papel seguindo as marcações projetadas (Gégori Castelhano e Bruna Gonçalves, 2016). 


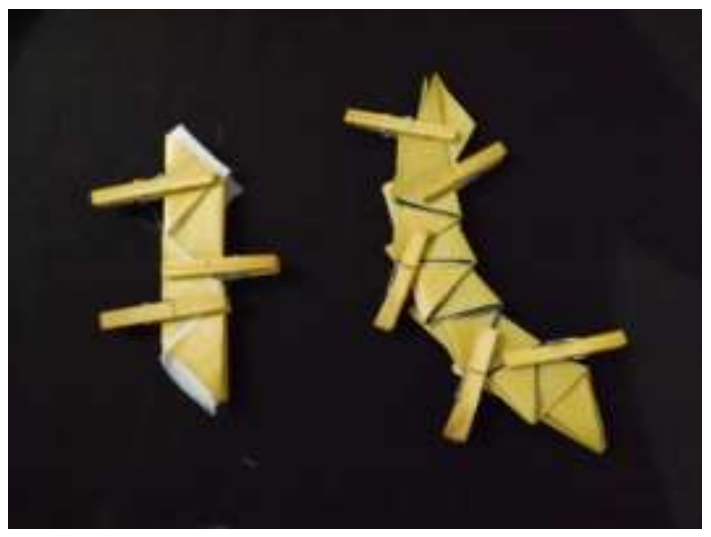

Figura 2: Molde de papel com tecido: preparação para ação térmica. (Gégori Castelhano e Bruna Gonçalves, 2016).

O resultado obtido (figura 3 ) permitiu a realização de testes que corroboraram com a sistematização do método. Este foi aplicado em uma superfície maior que permitiu a construção da Membrana.

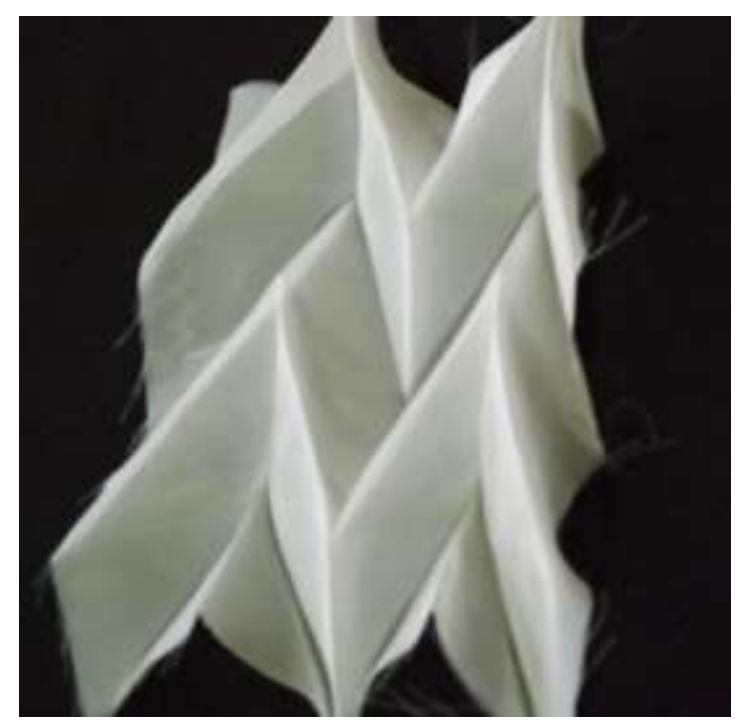

Figura 3: Tecido plissado: resultado do teste de plissagem artesanal em tecido 100\% poliéster. (Gégori Castelhano e Bruna Gonçalves, 2016).

\section{A Membrana}

A criação da membrana percorreu o caminho das experimentações, que suplantaram os esboços iniciais no papel. A cada obstáculo construtivo, superávamos com novas propostas, sempre mantendo a característica vestível e flexível, que permitisse a transformação de uma vestimenta em diferentes formas e usos. 
Recaíamos sempre em questões iniciais de grupo, advindas da leitura de Maffesoli (2014) quando ele fala das relações entre tribos urbanas e o novo nomadismo, que nos colocou diante do binômio público e privado. Já Bachelard (1990) nos intrigou com suas colocações sobre interior e exterior. O exercício de livre pensar que os textos proporcionaram, encaminhou o grupo para uma inquietante vontade de experimentar objetos, que trabalhassem a interioridade em detrimento à exterioridade do mundo. $\mathrm{O}$ resultado foi uma peça poética, onde $\mathrm{O}$ indivíduo se transforma de casulo em humano, mantendo o interior sensorial diante de um exterior pleno de estímulos. A interação entre sujeito e objeto permitiu a transformação, expansão e contração, e as diferentes formas que surgiram e que não foram inicialmente pensadas no projeto.

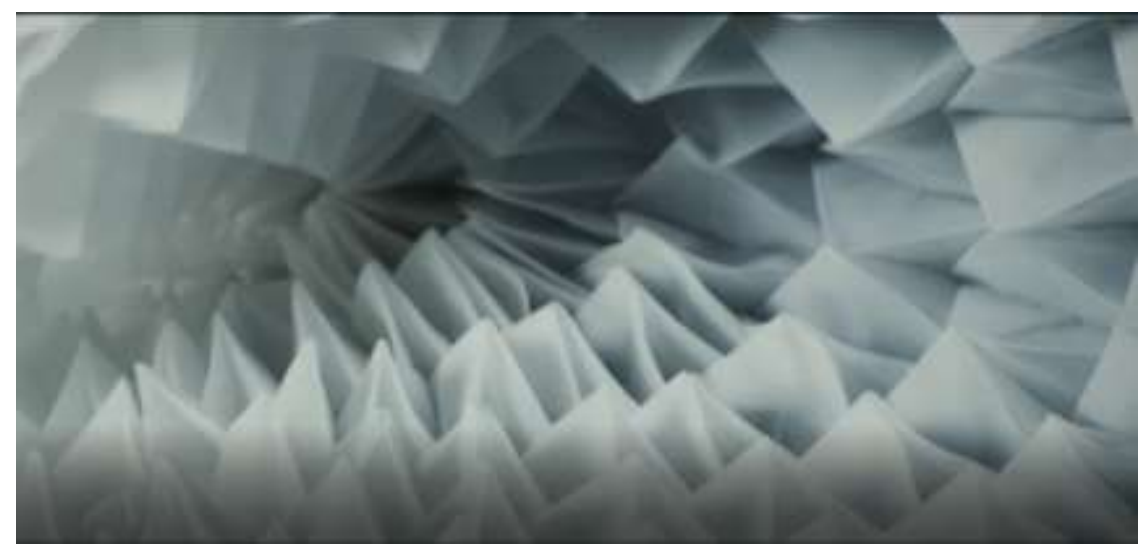

Figura 4: Membrana: a leveza do tecido permitiu um interior sensorial e suave (Gégori Castelhano e Bruna Gonçalves, 2016).

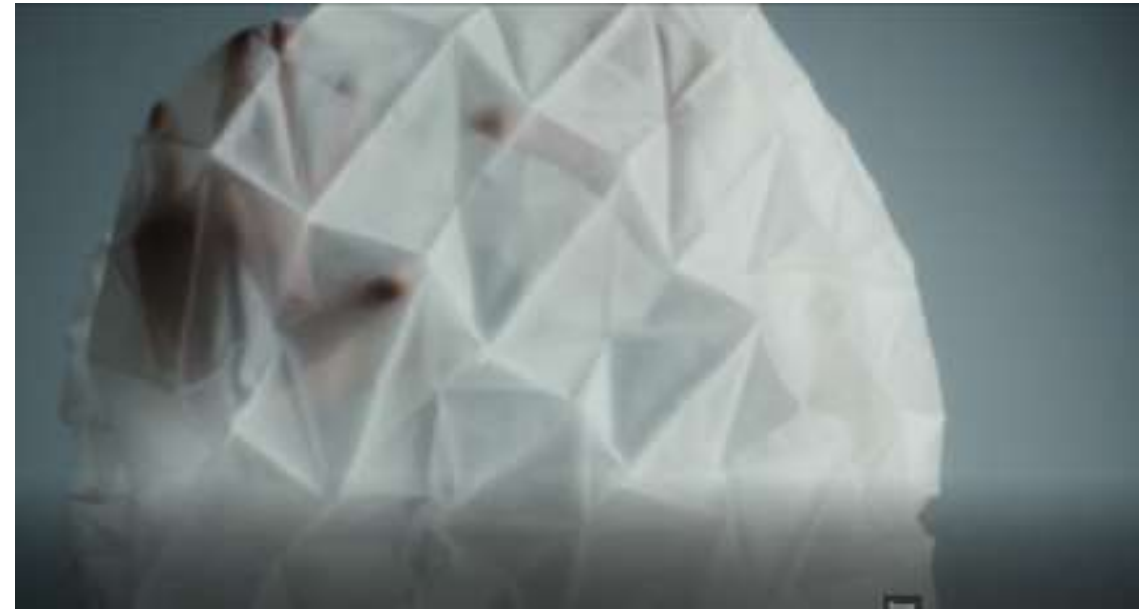

Figura 5: Membrana: casulo (Gégori Castelhano e Bruna Gonçalves, 2016). 


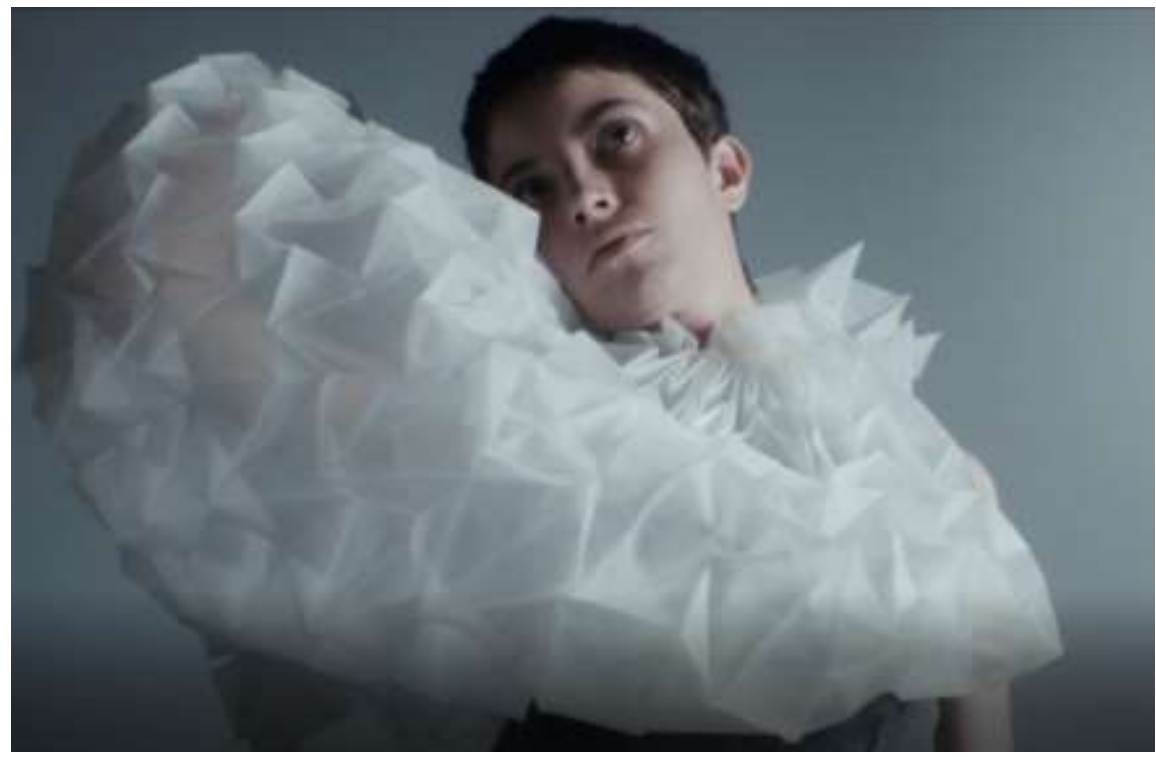

Figura 6: Membrana: rompimento do casulo (Gégori Castelhano e Bruna Gonçalves, 2016).

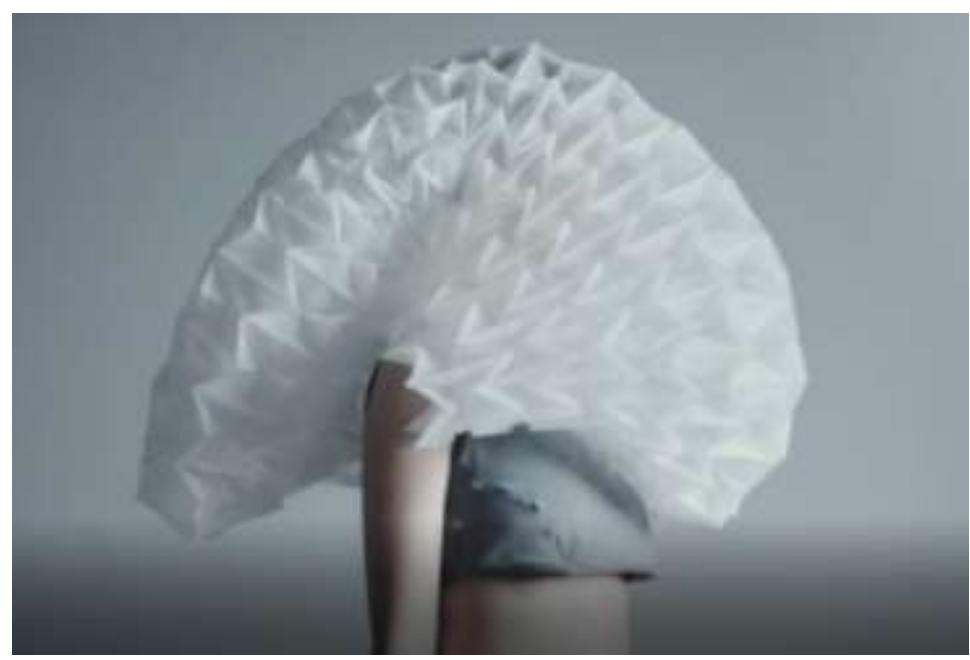

Figura 7: Membrana: retorno - interior X exterior (Gégori Castelhano e Bruna Gonçalves, 2016).

\section{Considerações finais}

Ao longo da série de encontros do grupo Cor e Forma, permeada por leituras e práticas experimentais, cresceu o interesse em relação à construção de objetos mutáveis e adaptáveis a diferentes situações. As questões mais importantes consideradas nas discussões foram sobre "interior e exterior" - numa abordagem existencial - e "dentro e fora" - espacialmente falando -. Isto aconteceu, porque as entendemos como fonte principal da dualidade de um objeto que é transformado conforme a situação, o local e o momento. A Membrana foi construída como um objeto poético que coloca o sujeito diante destas questões e o incita a experimentar fisicamente, sentimentos provocados pela textura, maciez, flexibilidade, abertura e fechamento. 
Como aprendizado, foi realizado um percurso criativo que motivou os alunos a superarem os obstáculos. Estimulou a adaptação de métodos construtivos artesanais e milenares, e a utilização de materiais facilmente encontrados em nossa realidade, o que levou as experimentações a um nível de satisfação elevado. Neste quesito, trabalhar com pouca tecnologia e baixo custo, mostrou para os envolvidos, a viabilidade de criar e construir objetos intrigantes e diferenciados. A manipulação da membrana e seu desdobramento em várias possibilidades expandiram na manifestação poética dos registros fotográfico e fílmico realizados pelo o grupo com parceiros no Bacharelado em Cinema e no de Música, do Instituto de Artes e Design, da Universidade Federal de Juiz de Fora, MG, que colaboraram com a realização deste projeto.

Os desdobramentos futuros são muitos. Pensamos em ampliar as experimentações práticas para vestimentas que se expandam e se adaptam às várias possibilidades de uso e que promova, no sujeito, a sensação de coautoria no ato de vestir e manipular a veste. Paralelamente, o aprofundamento da revisão bibliográfica e da observação comportamental se faz necessário para melhor entender como tais objetos impactariam na vida das pessoas. Desta forma, acreditamos contribuir para a criação de uma indumentária sensorial e que seja capaz de expandir as possibilidades de experimentação na moda. 


\section{Referências}

BACHELARD, Gaston. A Terra e os Devaneios do Repouso. Ensaio sobre as imagens da intimidade. São Paulo: Martins Fontes, 1990

ERNER, Guilhaume. Vítimas da moda? Como a criamos, porque a seguimos. São Paulo: Editora Senac São Paulo, 2005.

GASSEL, Frans van. Handstorm principles for creative and collaborative working. Einddhoven: Technische Universiteit Eindhoven, 2016.

MAFFESOLI, Michel. O tempo das tribos: o declínio do individualismo nas sociedades de massa. Rio de Janeiro: Forense, 2014.

MIURA, Koryo. The Science of Miura-ori: a review. Fourth International Meeting of Origami Cience, Mathematics, and Education. Editor: Robert J.Lang. ISBN 978-1-4398-7104-1

STACHEL, Hellmuth. Remarks on miura-ori, a japanese folding method. International Conference on Engineering Graphics and Design. Technical University of Cluj-Napoca, 2009.

YÁZIGI, Eduardo. Deixe sua estrela brilhar: criatividade nas ciências humanas e no planejamento. São Paulo: CNPq/Editora Plêiade, 2005. 